\title{
Effect of Cristobalite on the Strength of Sintered Fused Silica Above and Below the Cristobalite Transformation
}

\author{
Ryan C. Breneman $^{\dagger * *}$ and John W. Halloran** \\ Department of Material Science and Engineering, University of Michigan, Ann Arbor, Michigan
}

\begin{abstract}
Porous fused silica ceramics which had been partially devitrified to cristobalite were stronger at $350^{\circ} \mathrm{C}$ in the beta-cristobalite stability range, but weaker at $25^{\circ} \mathrm{C}$ after the transformation to alpha-cristobalite. The tensile strength distribution for different cristobalite fractions are compared for three types of specimens. These were beta-cristobalite samples which had never been transformed to alpha-cristobalite; roomtemperature samples with alpha-cristobalite; and samples at $350^{\circ} \mathrm{C}$ which had retransformed to beta-cristobalite after prior transformation to alpha-cristobalite. The alpha-cristobalite samples displayed $50 \%-75 \%$ the strength of samples tested on beta and the difference in strength was dependent on cristobalite content. Specimens retransformed to beta-cristobalite had strength similar to virgin specimens. Microcracking associated with the transformation to alpha-cristobalite contributes to the strength changes but cannot fully explain the impact of the beta-alpha transformation on strength.
\end{abstract}

\section{Introduction}

$\mathrm{F}$ OR at least a century it has been known that devitrification of amorphous fused silica to cristobalite weakens sintered silica. ${ }^{1,2}$ This weakening is typically attributed to microcracking of the cristobalite caused by the phase transition from the high-temperature, cubic beta-cristobalite polymorph to the low-temperature, tetragonal alpha-cristobalite. The transformation to alpha, occurring near $250^{\circ} \mathrm{C}$, has approximately a $5 \%$ volumetric reduction, which is known to cause microcracking. ${ }^{3,4}$ The effect of cristobalite on the strength of sintered silica was reported for slip cast porous silica by Walton and Paulos ${ }^{5}$ and by Wan et al. on sintered gel cast silica. ${ }^{6}$ Cristobalite lowered the strength of the silica. It is plausible to attribute the weakening of cristobalite on cooling to microcracks.

Porous sintered silica is an important refractory material, often used in the investment casting of superalloy airfoils. In service, the fused silica is crystallized to beta-cristobalite to suppress sintering shrinkage and creep deformation. ${ }^{7-11} \mathrm{Kaz}-$ emi et al. and Kim et al. have independently reported on the flexural strength of partially crystallized and uncrystallized material, but they did so in refractory mixtures including zircon and other additives. ${ }^{8,9,12}$ Taylor et al. investigated the role of cristobalite development on sintering shrinkage at high temperature. ${ }^{11}$ Bae discusses the strength of sintered silica produced by ceramic stereolithography. ${ }^{13}$ Although cristobalite reduces the room-temperature strength of silicabased investment casting molds, this weakening is a necessary

V. Sglavo-contributing editor

Manuscript No. 34832. Received April 9, 2014; approved January 15, 2015.

* Member, The American Ceramic Society.

**Fellow, The American Ceramic Society.

${ }^{\dagger}$ Author to whom correspondence should be addressed. e-mail: breneman@umich.edu trade off for the creep and sintering suppression provided by the crystalline phase. For this application, the cristobalitecontaining ceramics are cooled to room temperature, then reheated to transform back to beta-cristobalite. It is not clear how the strength would respond to if the cristobalite were heated to reverse the transformation.

In this study, we consider porous sintered silica which has partially devitrified to cristobalite, with emphasis on the effect of the cristobalite transformation on strength. The strength is measured at $350^{\circ} \mathrm{C}$, above the beta-to-alpha transformation temperature, in material which was never cooled following cristobalite formation and compared with the room temperature strength, below the beta-alpha transition temperature. To our knowledge the strength of material containing beta-cristobalite which had never been cooled through the beta-alpha transition has not been previously reported. Finally, we examine the strength of partially crystallized silica which had been cooled to alpha-cristobalite, then heated to $350^{\circ} \mathrm{C}$ and converted back to beta-cristobalite.

\section{Experimental Procedure}

\section{(1) Methods}

Disks of sintered silica were prepared under conditions to achieve similar porosities, but various degrees of devitrification to cristobalite. The strength of these were determined in the stability range of beta-cristobalite at $350^{\circ} \mathrm{C}$ (Condition A, labeled "beta"); after transformation to alpha-cristobalite at room temperature (Condition B, labeled "alpha:); and for samples that had transformed to alpha, but were reheated to return to beta-cristobalite and tested at $350^{\circ} \mathrm{C}$ (Condition $\mathrm{C}$, labeled "alpha-beta-alpha"). To assess whether the changes in strength was due to the cristobalite transformation, or simply the difference in testing temperature, we compare the strength fully amorphous specimens at $25^{\circ} \mathrm{C}$ and $350^{\circ} \mathrm{C}$.

\section{(2) Materials}

This study was conducted with a commercially available amorphous silica powder (TECO-Sphere-Microdust; CE Minerals, Greenville, TN). The powder is of $99.7 \%$ purity and is $95 \%$ amorphous with a $5 \%$ residual crystalline quartz fraction resulting from incomplete amorphization. The powder consists predominantly of 5-20 $\mu \mathrm{m}$ particles with a spherical morphology, with small $(<5 \%$ each) fractions of larger $20-50 \mu \mathrm{m}$ particles and fine submicrometer particles. Details of the powder characteristics were previously reported. ${ }^{14}$

\section{(3) Annealing and Testing Procedure}

The specimens were disks with approximate dimensions of $25 \mathrm{~mm}$ diameter and $6 \mathrm{~mm}$ thickness. These were produced by pressing the powder without binder at $30 \mathrm{MPa}$. To provide sufficient strength for handling the as-pressed pellets were annealed at $1100^{\circ} \mathrm{C}$ for $1 \mathrm{~h}$ in a box furnace. This presintering did not result in any crystallization and 
produced a stronger pellet with $25 \%$ open porosity as determined by Archimedes method, ASTM C-373-88.

Cristobalite phase fraction was determined by quantitative X-ray diffraction using an internal standard of $\mathrm{TiO}_{2}$ anatase by the method previously reported. ${ }^{14}$ The microstructure of the partially crystallized sintered silica was examined using polished cross sections. Annealed samples of known alphacristobalite content were impregnated with epoxy to fill the porosity, sectioned, and polished to $0.05 \mu \mathrm{m}$ finish. The microstructure of the sintered samples was investigated by scanning electron microscopy using backscattered electron imaging under conditions where there was some contrast between the amorphous silica and the cristobalite.

To determine the strength of silica with beta-cristobalite, we use samples which have never been cooled below the $250^{\circ} \mathrm{C}$ phase transformation, and so have not yet suffered the associated microcracking. These virgin beta-cristobalite specimens were prepared by sintering fused silica powder compacts at $1100^{\circ} \mathrm{C}$ in the mechanical testing machine to achieve a relative density of $88 \pm 2 \%$ and the desired cristobalite fraction. Each specimen was cooled to $350^{\circ} \mathrm{C}$ and its strength was determined as the "indirect tensile strength" using the Diametral Compression Test method. ${ }^{15-21}$ For this technique, a load applied along the diameter produces a tensile stress in the diameter plane which is as follows ${ }^{17}$ :

$$
\sigma_{\text {dia }}=\frac{2 P}{\pi D t}
$$

where $P$ is the applied load, $D$ is the disk diameter, and $t$ the disk thickness.

A high-temperature anneal and subsequent mechanical testing were conducted on an Instron (Norwood, MA) 4483 screw-driven electromechanical test frame and attached Applied Test Systems (Butler, PA) "clam-shell" style hightemperature furnace. Samples were annealed under ambient laboratory air at temperatures of $1100^{\circ} \mathrm{C}-1400^{\circ} \mathrm{C}$ for isothermal hold times of $20 \mathrm{~min}$ to $8 \mathrm{~h}$ on a bed of cristobalite powder on an alumina plate. Samples for Condition A, tested in the beta-cristobalite, phase were cooled to $350^{\circ} \mathrm{C}$ for testing. As the transition from beta-alpha-cristobalite is observed to occur between $200^{\circ} \mathrm{C}-273^{\circ} \mathrm{C},{ }^{3}$ the test temperature of $350^{\circ} \mathrm{C}$ allowed testing of samples in the stability range of beta-cristobalite. Samples for Condition B were tested in the alpha-cristobalite phase were cooled to room temperature (about $25^{\circ} \mathrm{C}$ ). Samples for Condition $\mathrm{C}$ were tested in the beta-cristobalite stability range, but had after previously passed the beta-alpha transition, referred to as beta-alpha-beta, were cooled to $25^{\circ} \mathrm{C}$ for $60 \mathrm{~min}$ and then reheated to $350^{\circ} \mathrm{C}$ for testing.

The samples were placed upright on an alumina platen with forceps and the furnace was closed. Contact with the sample was made between the lower alumina platen and the upper alumina push rod of the furnace to load the sample along the vertical diameter. Testing was conducted under displacement control at a crosshead speed of $0.015 \mathrm{~mm} / \mathrm{s}$. Following failure, the sample was removed from the furnace and inspected for their fracture mode. We only report the results from samples with an obvious vertical diametral fracture resulting from diametral tension, as the stress could be calculated with Eq. (1). Some specimens failed in compressive crushing or other modes for which the stress state was not known. These samples were discarded.

\section{Results}

Table I presents porosity, number of samples, and the median and mean strength values and Weibull parameters for samples with no cristobalite, a small amount (1\%-20\%), intermediate amounts $(20 \%-80 \%)$, and samples that are mostly cristobalite $(80 \%-100 \%)$ in the three conditions, A, B, and $\mathrm{C}$. The final density of the samples depended on the annealing time and temperature. It was not possible to separate the concurrent phenomena of sintering densification and crystallization to cristobalite. Samples annealed at $1100^{\circ} \mathrm{C}$, corresponding to $0 \%$ cristobalite phase fraction, had $25 \pm 1 \%$ open porosity. Samples annealed at $1200^{\circ} \mathrm{C}$, corresponding to $>0 \%$ but $<1 \%$ cristobalite phase fraction, had $23 \pm 1 \%$ open porosity. Samples annealed at $1275^{\circ} \mathrm{C}-$ $1375^{\circ} \mathrm{C}$, corresponding to $8 \%-92 \%$ cristobalite phase fraction, had $17 \pm 2 \%$ open porosity. Samples annealed at $1400^{\circ} \mathrm{C}$, corresponding to $100 \%$ cristobalite phase fraction, had $14 \pm 1 \%$ open porosity.

For each specimen we have the value of strength, cristobalite fraction, and sintered density. As there is considerable variation in the strength values, the strength data are presented as cumulative strength distributions, as fraction of specimens that are weaker than a particular strength value. The sets of tensile strengths are rank-ordered, expressed as a fraction of the population, and plotted directly so that the complete distributions can be compared for different ranges of cristobalite content. The differences between Conditions A, B, and C are shown by the shifting of the cumulative strength distributions. A twoparameter Weibull distribution was fit to the strength data.

\section{(1) Strength at $25^{\circ} \mathrm{C}$ and $350^{\circ} \mathrm{C}$ with $\mathrm{No}$ Cristobalite}

To establish whether testing temperature changes the strength we examined fully amorphous samples with no cristobalite. These samples were annealed at $1100^{\circ} \mathrm{C}$ where previous kinetic studies have shown cristobalite will not form. ${ }^{14}$ This was confirmed by X-ray diffraction, which showed no measurable cristobalite content. The porosity in these $1100^{\circ} \mathrm{C}$ samples was $25 \pm 1 \%$, so the strengths of these samples cannot be compared with the denser specimens sintered at higher temperature. Figure 1 shows the cumulative strength distribution for cristobalite-free material measured at $25^{\circ} \mathrm{C}$ compared with the strength measured at $350^{\circ} \mathrm{C}$. The

Table I. Mean and Median Observed Strength, Porosity, and Number of Observations $N$ for Selected Ranges of Cristobalite Content

\begin{tabular}{|c|c|c|c|c|c|c|c|}
\hline & $\%$ Cristobalite & Median $\sigma(\mathrm{MPa})$ & Mean $\sigma(\mathrm{MPa})$ & $\%$ Porosity & $N$ & Weibull modulus, m & Characteristic strength, $\sigma_{\mathrm{o}}$ \\
\hline & $1-20$ & 5.4 & 5.1 & $18 \pm 2$ & 24 & 2.7 & 5.7 \\
\hline & $80-100$ & 6.0 & 7.8 & $16 \pm 3$ & 25 & 2.4 & 8.8 \\
\hline \multirow[t]{2}{*}{ Condition B: alpha } & 0 & 0.46 & 0.50 & $25 \pm 1$ & 12 & - & - \\
\hline & $1-20$ & 2.9 & 3.8 & $18 \pm 2$ & 22 & 2.1 & 4.2 \\
\hline \multirow[t]{2}{*}{ Condition C: beta-alpha-beta } & $20-80$ & 9.2 & 9.1 & $18 \pm 2$ & 22 & - & - \\
\hline & $80-100$ & 5.7 & 7.3 & $14 \pm 1$ & 5 & - & - \\
\hline
\end{tabular}




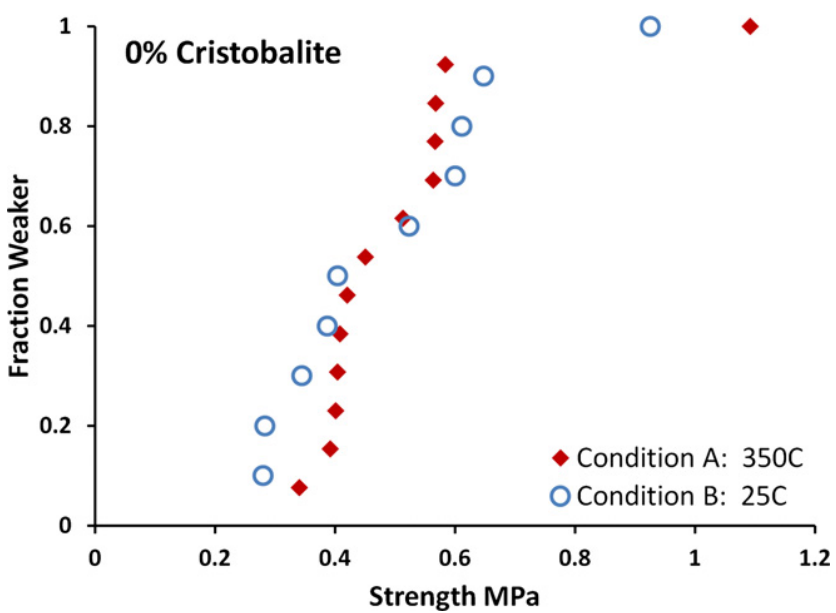

Fig. 1. Cumulative strength distribution for samples with no cristobalite at $25^{\circ} \mathrm{C}$ and at $350^{\circ} \mathrm{C}$.

cumulative distribution displays all the individual strength values. The uncertainty of each value is about $2 \%$, based on the accuracy of the dimensions and fracture load measurements. No error bars are shown in Fig. 1, as the error bars are smaller than the symbols. The strength distributions are very similar at these two temperatures, suggesting that there is little effect of temperature itself in the range $25^{\circ} \mathrm{C}-350^{\circ} \mathrm{C}$. Thus, we might expect for specimens that contain cristobalite, that the difference between the $350^{\circ} \mathrm{C}$ strength (tested as beta-cristobalite) and the $25^{\circ} \mathrm{C}$ strength (tested as alpha-cristobalite) reflects the impact of the phase transformation, and not a difference in the strength of the amorphous silica itself.

\section{(2) Strength of Specimens with Alpha-Cristobalite Compared to Beta-Cristobalite}

The strength of the porous silica is not very strongly dependent on the amount of cristobalite. Figure $2 \mathrm{a}$ compares the strength distributions at $350^{\circ} \mathrm{C}$ (Condition A with betacristobalite) for specimens with a small amount of cristobalite $(1 \%-20 \%)$, and intermediate amount of cristobalite $(20 \%-80 \%)$, and a substantially cristobalite $(80 \%-100 \%)$. The distributions for the latter two are quite similar, and are somewhat stronger than the samples with a small cristobalite fraction. In the alpha-cristobalite case (Condition B), the strength distributions do not change significantly with cristobalite content, as shown in Fig. 2b. The data presented in Fig. 2 must be considered carefully as the porosity varied with cristobalite content. It was found to be impossible to separate the concurrent phenomena of sintering and crystallization to cristobalite. As a result the material with higher cristobalite content is also denser. The mean porosity values can be seen in Table I. There is a significant difference in the strength distributions for Condition A compared to Condition B. Figures 3(a)-(c) compares the strength at $350^{\circ} \mathrm{C}$ (Condition A with beta-cristobalite) with the strength at $25^{\circ} \mathrm{C}$ (Condition B with alpha-cristobalite). The strength data are plotted as cumulative distributions for samples with a small amount of cristobalite, 1\%-20\% [Fig. 3(a)], samples with an intermediate amount of cristobalite, $20 \%-80 \%$ [Fig. 3(b)], and samples that are mostly cristobalite, $80 \%-$ $100 \%$ [Fig. 3(c)]. In all cases, the strength distribution lies to the left for alpha-cristobalite. For samples with a small amount of cristobalite, $1 \%-20 \%$, the material tested as virgin beta-cristobalite is somewhat stronger than the material tested as alpha-cristobalite having passed the beta-alpha transition, with the material tested as alpha possessing $76 \%$ the mean strength of material tested as beta-cristobalite. In samples with moderate cristobalite content, $20 \%-80 \%$, the material tested as beta-cristobalite is significantly stronger
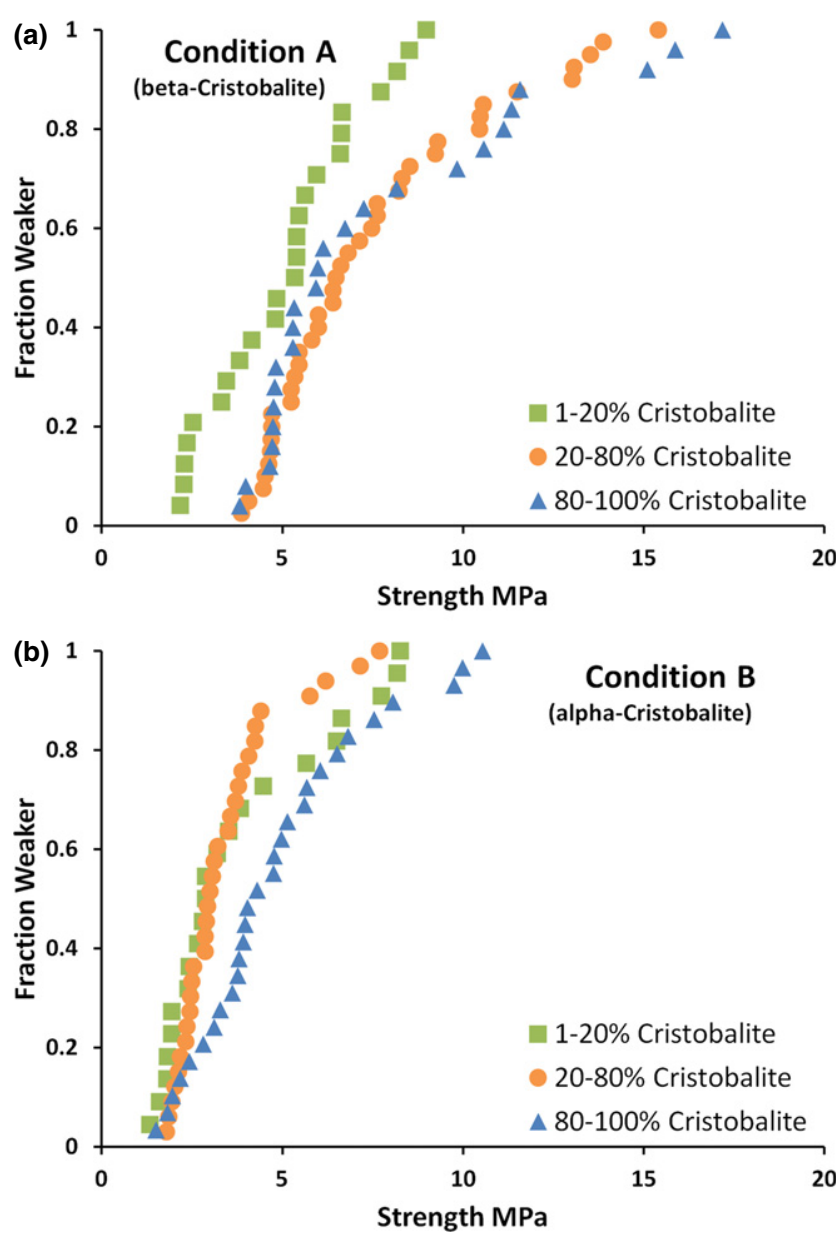

Fig. 2. Cumulative distribution of observed strengths for samples with varying amount of cristobalite (a) effect of cristobalite content on strength in Condition A $\left(350^{\circ} \mathrm{C}\right)$ as beta-cristobalite and (b) Condition $\mathrm{B}\left(25^{\circ} \mathrm{C}\right)$ as alpha-cristobalite. Note that porosity varies with cristobalite content.

than the material tested as alpha-cristobalite, with material tested as alpha-cristobalite possessing $52 \%$ the mean strength of material tested as beta-cristobalite. In samples nearly or wholly cristobalite, $80 \%-100 \%$, the samples tested as betacristobalite are significantly stronger than those tested as alpha, but the difference is smaller than for samples with a moderate cristobalite content. For these samples the material tested as alpha possessed $63 \%$ the mean strength of material tested as beta-cristobalite.

This same data are presented as a two-parameter Weibull plots in Figs. 4(a)-(c). A regression line fit through the data shows that it is not well represented by a single two-parameter Weibull distribution. However, it is apparent from the Weibull plots that the material tested as beta is stronger than the material tested as alpha, and the difference in strength is greatest for moderate cristobalite content, $20 \%-80 \%$. The approximate values for the shape parameter or Weibull modulus $(\mathrm{m})$ and characteristic strength $\left(\sigma_{\mathrm{o}}\right)$ are reported in Table I. Samples with small amounts of cristobalite display [Fig. 4(a)] $\mathrm{m} \sim 2.7$ and $\sigma_{\mathrm{o}} \sim 5.7 \mathrm{MPa}$ when the cristobalite in beta phase (Condition $\mathrm{A}$ ), and $\mathrm{m} \sim 2.1$ and $\sigma_{\mathrm{o}} \sim 4.2 \mathrm{MPa}$ when the cristobalite in alpha phase (Condition B). Specimens with intermediate amounts of cristobalite [Fig. 4(b)] $\mathrm{m} \sim 2.6$ and $\sigma_{\mathrm{o}} \sim 9.3 \mathrm{MPa}$ when the cristobalite in beta phase (Condition A), and $\mathrm{m} \sim 6.0$ and $\sigma_{\mathrm{o}} \sim 2.9 \mathrm{MPa}$ when the cristobalite in alpha phase (Condition B). Specimens that are mostly cristobalite [Fig. 4(c)] were fit with the parameters $\mathrm{m} \sim 2.4$ and $\sigma_{\mathrm{o}} \sim 8.8 \mathrm{MPa}$ when the cristobalite in beta phase (Condition A), and $\mathrm{m} \sim 2.4$ and $\sigma_{\mathrm{o}} \sim 1.5 \mathrm{MPa}$ when the cristobalite in alpha phase (Condition $\mathrm{B}$ ). 
(a) $1-20 \%$ Cristobalite
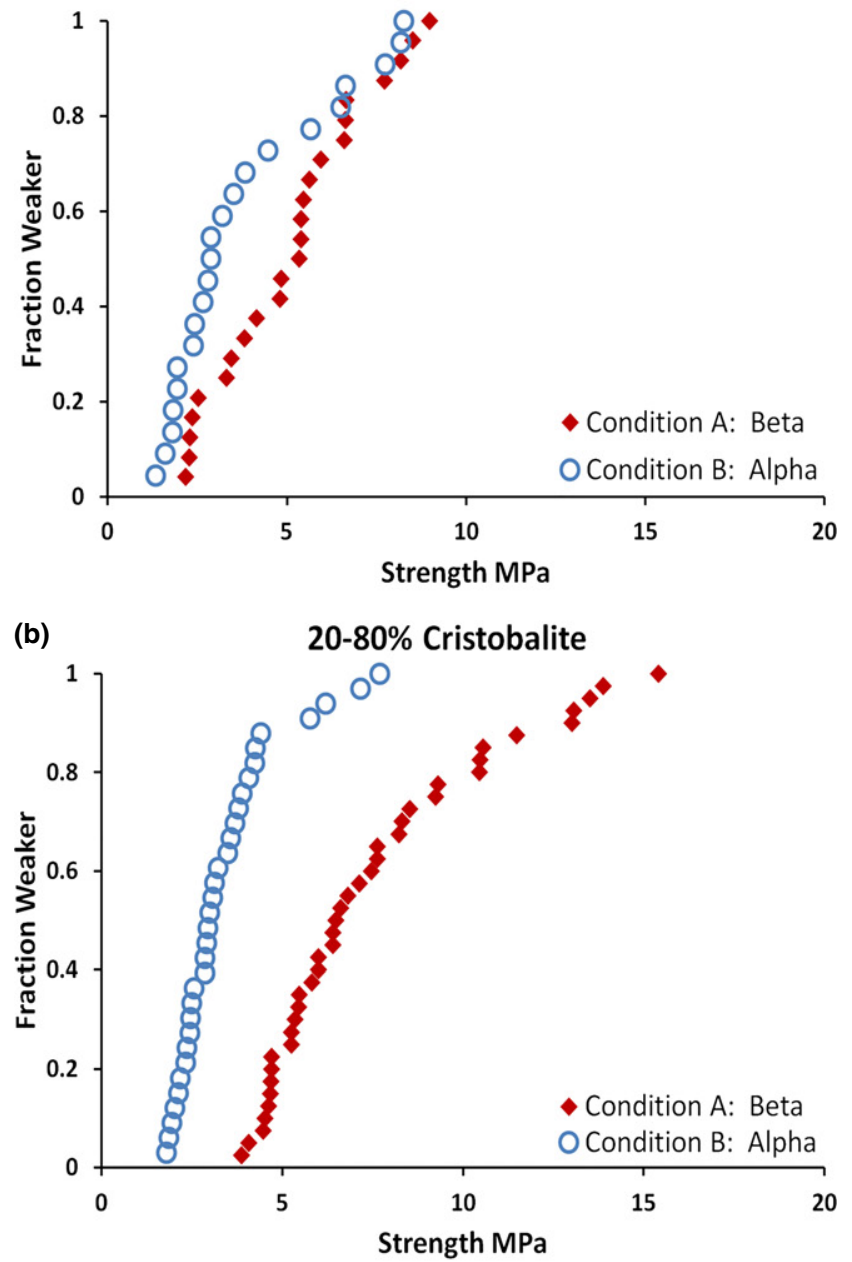

(c)

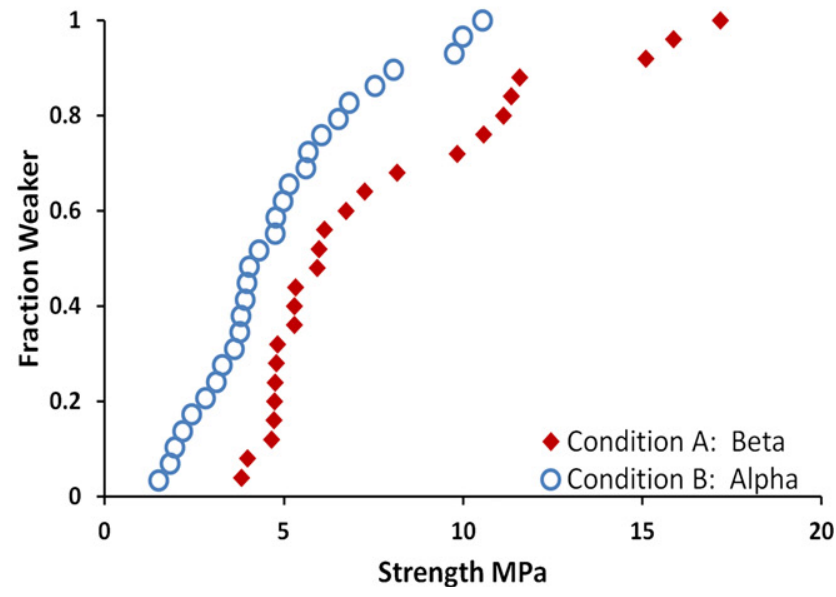

Fig. 3. Cumulative distribution of observed strengths for samples with varying amount of cristobalite illustrating difference in strength between samples tested as beta-cristobalite and alpha-cristobalite. (a) Small amount of cristobalite, $1 \%-20 \%$ (b) Moderate amount of cristobalite, $20 \%-80 \%$ (c) Mostly cristobalite, $80 \%-100 \%$.

\section{(3) Strength Following the Beta-Alpha Transition}

Many times refractories used in casting applications are fired, cooled, and subsequently heated during casting. Presumably the first transformation to alpha-cristobalite creates microcracks. Subsequent reheating would transform the cristobalite back to the beta phase, but it is not known what effect the micro-cracks formed during the transition to alpha-cristobalite have in material that has been reheated to (a)

$1-20 \%$ Cristobalite
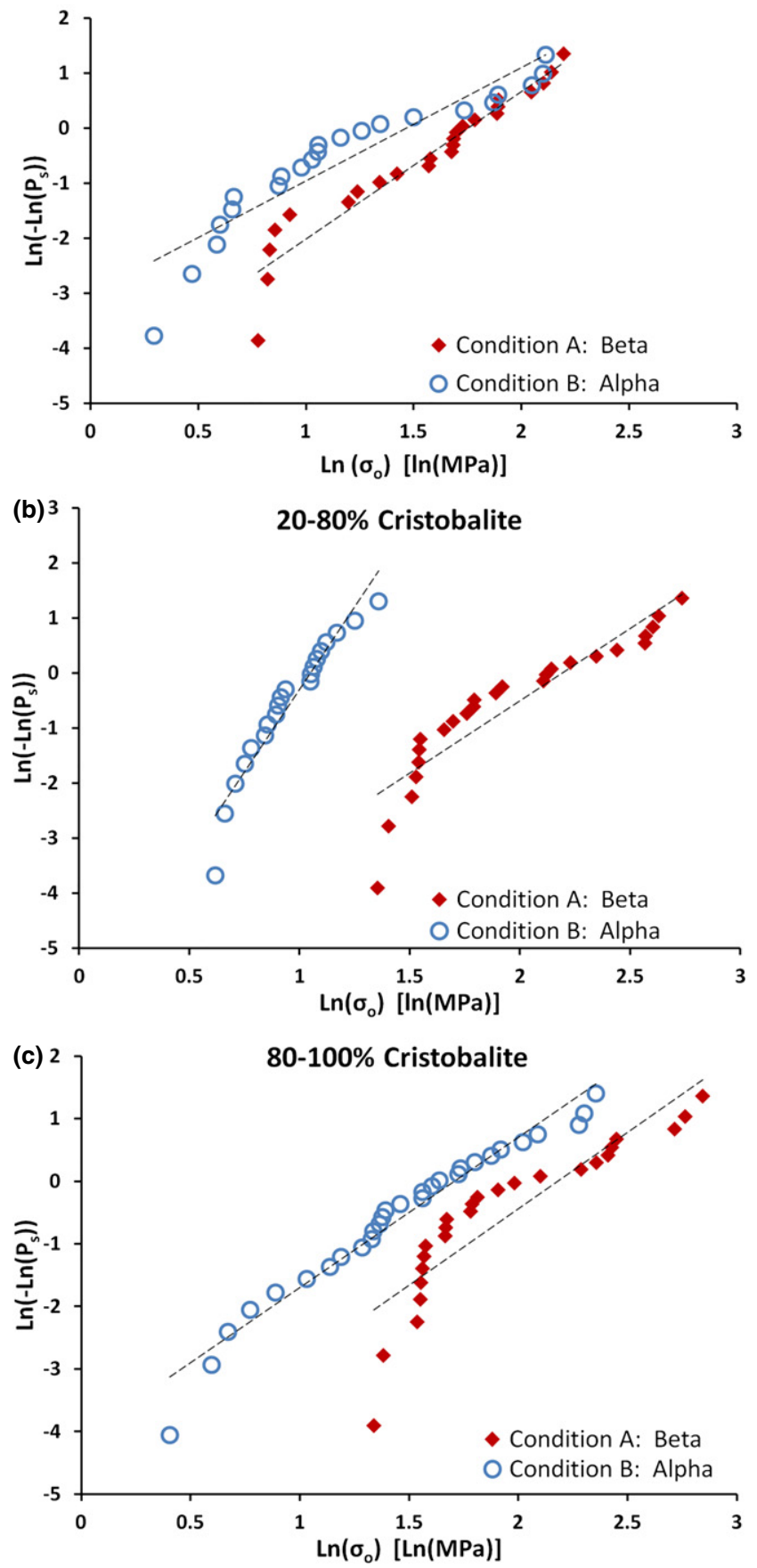

Fig. 4. Strength distribution as two-parameter Weibull distribution for samples tested as beta-cristobalite compared to alpha-cristobalite for varying cristobalite content. (a) Small amount of cristobalite, $1 \%-20 \%$. (b) Moderate amount of cristobalite, $20 \%-80 \%$. (c) Mostly cristobalite, $80 \%-100 \%$.

the beta phase. To evaluate strength of sintered silica in the beta-cristobalite phase in material which had been previously cooled through the transformation to alpha-cristobalite, samples were cooled to $25^{\circ} \mathrm{C}$ following annealing, and then reheated to $350^{\circ} \mathrm{C}$ for testing. These samples are referred to as beta-alpha-beta in reference to their transformation history. In Fig. 5 the strengths of these beta-alpha-beta samples tested at $350^{\circ} \mathrm{C}$ are displayed alongside that of samples tested at $25^{\circ} \mathrm{C}$ (alpha) and samples tested at $350^{\circ} \mathrm{C}$ having never been cooled (beta). When the sintered silica is highly crystalline, $80 \%-100 \%$ cristobalite, the beta-alpha-beta samples have a strength distribution which falls between the "alpha" samples tested at $25^{\circ} \mathrm{C}$ and the "beta" samples 


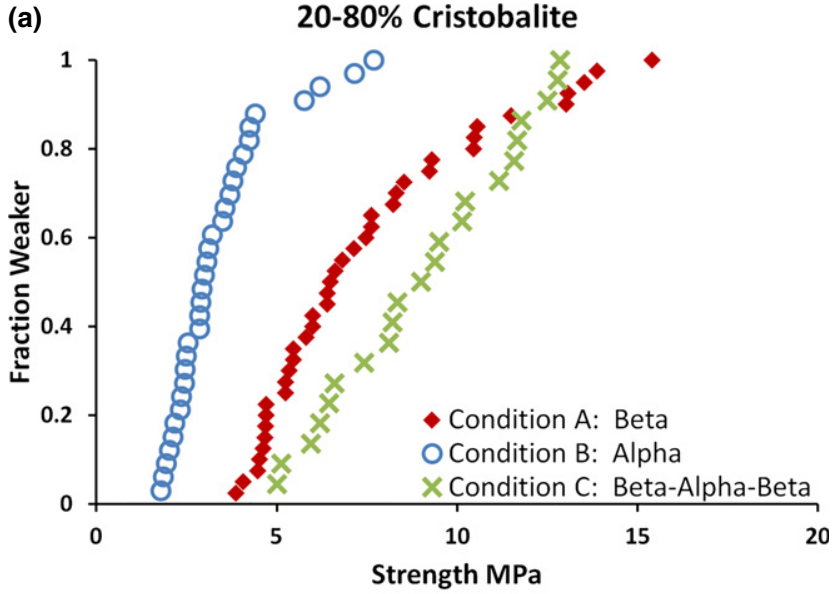

(b) $\quad 80-100 \%$ Cristobalite

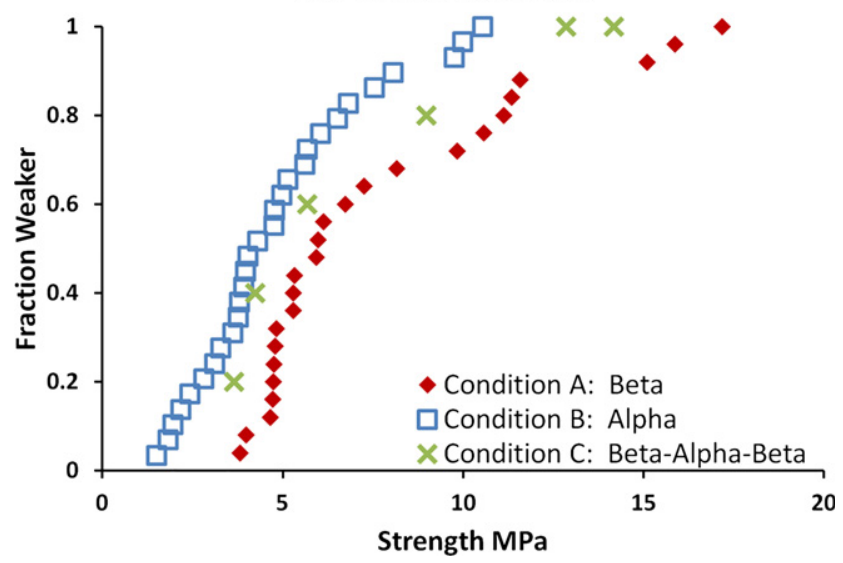

Fig. 5. Strength distribution comparing samples tested as betacristobalite having previously been cooled through beta-alpha transition (beta-alpha-beta) compared to samples tested as untransformed beta and as alpha-cristobalite. (a) Moderate cristobalite content, $20 \%-80 \%$ (b) mostly cristobalite, $80 \%-100 \%$.

tested at $350^{\circ} \mathrm{C}$. The retransformed specimens tend to be stronger than specimens with alpha-cristobalite, but not as strong as the specimens which had never transformed. For samples with samples with moderate cristobalite content, $20 \%-80 \%$, these beta-alpha-beta samples appear to be slightly stronger than the beta material which had never been cooled. This result runs counter to a simple view of microcracking reducing strength since the beta-alpha-beta samples have been microcracked on cooling to alpha-cristobalite but have actually increased in strength upon reheating to betacristobalite.

\section{(4) Microstructure}

The sintered microstructure of a sample sintered at $1325^{\circ} \mathrm{C}$ with $55 \%$ cristobalite content as imaged by secondary electron can be seen in Fig. 6. The powder still retains its characteristic spherical particle morphology. The material is lightly sintered with limited particle to particle contact, retaining the appearance of sintered particles rather than a porous solid. The polished section features large particles in a matrix of the finer particles. The larger particles are poorly bonded to the matrix. Along the periphery of the large particles, the matrix appears to have shrunk away during sintering, leaving fissures. Microcracks are obvious in the large particles. Figure 6(b) is a fracture surface. The fracture has passed around the large spherical particles and we see no cracks passing through these larger particles. The fracture

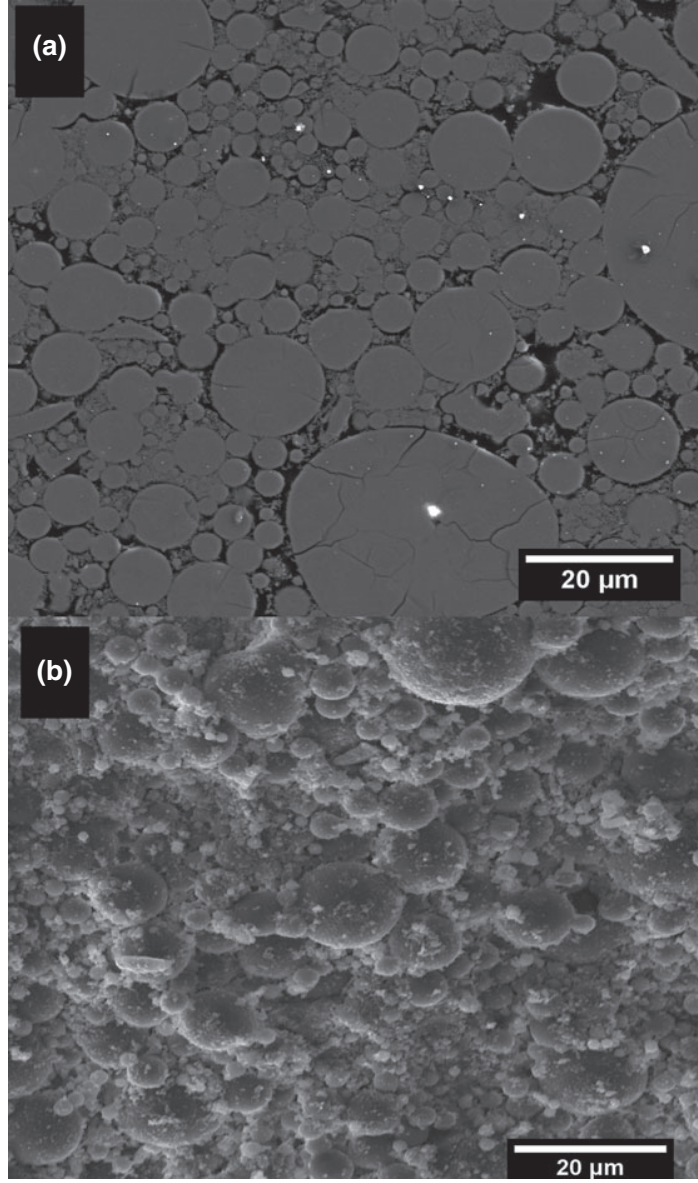

Fig. 6. SEM microstructure of sample sintered at $1325^{\circ} \mathrm{C}$ with $55 \%$ cristobalite content by QXRD imaged by secondary election, SE, imaging. (a) Polished cross-section (b) fracture surface.

path does not go through the large particles, so the microcracks visible in the polished surface are not fracture origins.

Using backscatter electron imaging, the distribution of cristobalite in the large particles can be seen with contrast provided by the small difference in density between the crystalline and amorphous phase. Figure 7 shows the progression of crystallization as cristobalite forms at the surface of the large particles and develops into a shell around the amorphous core of the particles. It can be seen that at $50 \%$ cristobalite content a well-developed cristobalite shell surrounds an amorphous core. In the particles displaying this core-shell morphology the cristobalite shell displays extensive microcracking. The cracks are seen to extend from the surface and terminate in the vicinity of the crystalline-amorphous boundary. This microcracking presumably occurs as a result of the beta-alpha transition. There is not enough contrast between to determine if the fine particle matrix has retained amorphous silica or if it is fully cristobalite. It is plausible that the fine particle matrix is entirely converted cristobalite.

\section{Discussion}

We are confident that the strength difference can be related to cristobalite, because the strength of the amorphous sintered silica (with no cristobalite) was essentially the same at $25^{\circ} \mathrm{C}$ and $350^{\circ} \mathrm{C}$. Thus for cristobalite-containing samples, we can attribute differences in the $25^{\circ} \mathrm{C}$ and $350^{\circ} \mathrm{C}$ strength to differences in alpha-cristobalite and beta-cristobalite. The transition to alpha-cristobalite significantly reduced the strength of partially crystalline sintered silica relative to specimens with beta-cristobalite. 


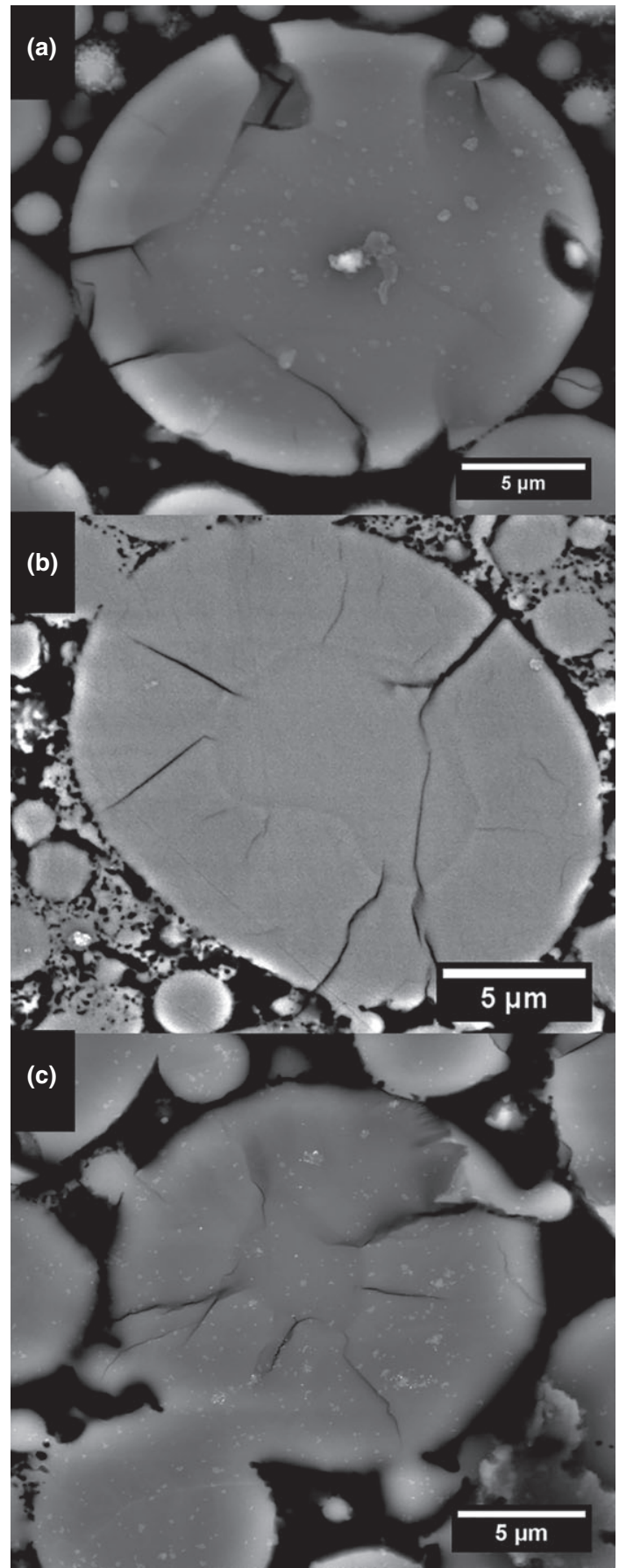

Fig. 7. SEM of microstructure by backscatter electron, BSE, illustrating development of cristobalite morphology. Cristobalite is observed to surface nucleate and grow as a crystalline "shell" around the amorphous silica "core." Cristobalite content of (a) $11 \%$, (b) $50 \%$, (c) $84 \%$.

The sintered silica with alpha-cristobalite was significantly weaker than material with the same amount of beta-cristobalite. This is consistent with the hypothesis that microcracking from the transformation to alpha-cristobalite reduces the strength. The finding that the strength of material tested as alpha-cristobalite has $50 \%-75 \%$ of the strength of material tested as beta is comparable to the results reported by Kazemi et al. who found silica ceramics heat-treated to transform to cristobalite had $75 \%$ of the flexural strength of those treated at lower temperature, which presumably had not crystallized. The weakening effect seems to be greatest for intermediate cristobalite contents as seen in Figs. 3 and 4.

Microcracks are easily observed on the larger spherical particles. Cristobalite nucleates on the surface of the sintered particles and over the course of transformation forms a crystalline shell over an amorphous core as observed by others. ${ }^{7,8}$ Upon transformation, beta-cristobalite transforms into multiple misoriented grains of alpha-cristobalite, ${ }^{22,23}$ with a $5 \%$ volumetric decrease. For the case of large particles, such as those developing a core-shell morphology in Fig. 7, this crystalline shell contracts around the static amorphous core on transition from beta-cristobalite to alpha-cristobalite resulting in microcracking. However, the microcracks in the crystalline shells of the large particles are not necessarily related to the strength changes. It is clear from Fig. 6 that the fracture surface does not pass through the large particles. Therefore microcracking of the larger particles does not play the dominant role in determining strength. It is likely that the fine particle matrix also had microcracked alpha-cristobalite, but we have no direct evidence for microcracks in the fine particle matrix. It is also unknown if the fine matrix develops a core-shell morphology of cristobalite forming around an amorphous core as in the case of the larger particles. Unfortunately, it was not possible to resolve the small density difference between the amorphous and crystalline material in the fine particle matrix. We are left with direct observations of the cracking phenomena of the large particles which are not involved in failure, but, unfortunately, we were unable to resolve cracking or cristobalite-amorphous silica interfaces in the fine loosely sintered matrix due to the small particle size and low sintered density of the material.

If microcracks from the alpha transformation were the dominant flaw in the sintered silica, one might expect that retransforming the cristobalite to the beta phase would close the cracks, but not necessarily heal the cracks. The microcracks which were opened on transition to alpha-cristobalite on first cooling would presumably close following the corresponding volume expansion on transformation back to beta-cristobalite. However, it is not likely that the damage associated with the cracks could be healed at a temperature as low as $350^{\circ} \mathrm{C}$, which is very much lower than the characteristic softening point of amorphous silica. We might expect that the retransformed material at $350^{\circ} \mathrm{C}$ would be stronger than the room temperature alpha-cristobalite, weaker than the virgin beta-cristobalite material at $350^{\circ} \mathrm{C}$. However, we observe that the strength distribution shifts to higher strength when room-temperature samples are heated to retransform the cristobalite to beta-cristobalite. The specimens that are mostly cristobalite $(80 \%-$ $100 \%$ ) are slightly weaker than the virgin beta-cristobalite specimens, but stronger than the alpha-cristobalite specimens tested at room temperature, which is consistent with this expectation. However, samples with $20 \%-80 \%$ cristobalite which have been cooled to alpha-cristobalite and reheated to $350^{\circ} \mathrm{C}$ and tested in the beta-cristobalite stability field are in fact stronger than those virgin samples that have never been cooled through the beta-alpha transition. The apparent strengthening observed in the material reheated to beta-cristobalite is not consistent with the hypothesis that strength of silica containing cristobalite is entirely associated microcracking from the transformation to alpha-cristobalite.

\section{Conclusions}

The strength of fully amorphous porous sintered silica is the same at $350^{\circ} \mathrm{C}$ and $25^{\circ} \mathrm{C}$. Partially devitrified sintered fused silica containing cristobalite content is stronger at $350^{\circ} \mathrm{C}$ in the beta-cristobalite stability field and weaker at $25^{\circ} \mathrm{C}$, after the cristobalite transforms to alpha-cristobalite. Partially devitrified specimens cooled to alpha-cristobalite and subsequently reheated and tested at $350^{\circ} \mathrm{C}$ as beta-cristobalite was stronger than material that had never cooled to alpha-cristobalite. Strength is recovered upon transformation of alphacristobalite back to beta-cristobalite. The transformation to alpha-cristobalite is associated with microcracking, but the strength changes cannot be entirely attributed to microcracking. 


\section{Acknowledgments}

This research was supported by the Defense Advance Research Projects Agency (DARPA) under grant HR001-08-1-0075, Principal Investigator Suman Das, Georgia Institute of Technology, Program Officer W.S. Coblenz and the Office of Naval Research, Scientific Officer David Shifler.

\section{References}

${ }^{1}$ W. Crookes, "On the Devitrification of Silica Glass," Proc. R. Soc. Lond. Ser. A-Contain. Pap. Math. Phys. Character, 86 [588] 406-8 (1912).

${ }^{2}$ I. P. Swainson and M. T. Dove, "Molecular Dynamics Simulation of Alpha-Cristobalite and Beta-Cristobalite," J. Phys. Condens. Matter., 7 [9] 1771-88 (1995).

${ }^{3}$ R. B. Sosman, The Phases of Silica, Sosman Book. Rutgers University Press, New Brunswick, NJ, 1965.

${ }^{4}$ D. R. Peacor, "High-Temperature Single Crystal Study of Cristobalite Inversion," Z. Kristall., 138, 274-98 (1973).

${ }^{5}$ J. D. Walton and N. E. Paulos, "Slip Cast Fused Silica"; in No. ML-TDR64-195. Air Force Materials Laboratory, Wright-Patterson Air Force Base, $\mathrm{OH}, 1964$.

${ }^{6}$ W. Wan, J. Yang, J. Z. Zeng, L. C. Yao, and T. Qiu, "Effect of Solid Loading on Gelcasting of Silica Ceramics Using DMAA," Ceram. Int., 40 [1] 1735-40 (2014).

${ }^{7}$ A. A. Wereszczak, K. Breder, M. K. Ferber, T. P. Kirkland, E. A. Payzant, C. J. Rawn, E. Krug, C. L. Larocco, R. A. Pietras, and M Karakus, "Dimensional Changes and Creep of Silica Core Ceramics Used in Investment Casting of Superalloys," J. Mater. Sci., 37 [19] 4235-45 (2002).

${ }^{8}$ A. Kazemi, M. A. Faghihi-Sani, and H. R. Alizadeh, "Investigation on Cristobalite Crystallization in Silica-Based Ceramic Cores for Investment Casting," J. Eur. Ceram. Soc., 33 [15-16] 3397-402 (2013).

${ }^{9}$ A . Kazemi, M. A. Faghihi-Sani, M. J. Nayyeri, M. Mohammadi, and M. Hajfathalian, "Effect of Zircon Content on Chemical and Mechanical Behavior of Silica-Based Ceramic Cores," Ceram. Int., 40 [1, Part A] 1093-8 (2014).
${ }^{10}$ L. Y. Wang and M. H. Hon, "The Effect of Cristobalite Seed on the Crystallization of Fused Silica Based Ceramic Core - A Kinetic Study," Ceram. Int., 21 [3] 187-93 (1995).

${ }^{11}$ B. Taylor, S. T. Welch, and S. Blackburn, "Investigation into the Effect of Common Ceramic Core Additives on the Crystallization of Amorphous Silica," Mech. Prop. Perform. Eng. Ceram. Comp. VIII: Ceram. Eng. Sci. Proc., 34, 111-21 (2013).

${ }^{12}$ E.-H. Kim, G.-H. Cho, Y. Yoo, S. Seo, and Y.-G. Jung, "Development of a New Process in High Functioning Ceramic Core Without Shape Deformation," Ceram. Int., 39 [8] 9041-5 (2013).

${ }^{13}$ C. J. Bae, "Integrally Cored Ceramic Investment Casting Mold Fabricated by Ceramic Stereolithography," Materials Science and Engineering; Ph.D. Thesis, University of Michigan, Ann Arbor, MI, 2008

${ }^{14}$ R. C. Breneman and J. W. Halloran, "Kinetics of Cristobalite Formation in Sintered Silica Glass," J. Am. Ceram. Soc., 97, 2272-8 (2014).

${ }^{15} \mathrm{M}$. Mellor and I. Hawkes, "Measurement of Tensile Strength by Diametral Compression of Discs and Annuli," Eng. Geol., 5 [3] 173-225 (1971).

${ }^{16} \mathrm{H}$. Awaji and S. Sato, "Diametral Compressive Testing Method," J. Eng. Mater. Technol. Trans. ASME, 101 [2] 139-47 (1979).

${ }^{17}$ M. K. Fahad, "Stresses and Failure in the Diametral Compression Test," J. Mater. Sci., 31 [14] 3723-9 (1996).

${ }^{18}$ D. K. Shetty, A. R. Rosenfield, and W. H. Duckworth, "Mixed-Mode Fracture of Ceramics in Diamtetral Compression," J. Am. Ceram. Soc., 69 [6] 437-43 (1986)

${ }^{19}$ R. H. Marion and J. K. Johnstone, "Parametric Study of Diametral Compression Test for Ceramics," Am. Ceram. Soc. Bull., 56 [11] 998-1002 (1977).

${ }^{20}$ T. Woignier and J. Phalippou, "Mechanical Strength of Silica Aerogels," J. Non-Cryst. Solids, 100 [1-3] 404-8 (1988).

${ }^{21}$ K. Gopalakrishnan and J. J. Mecholsky, "Quantitative Fractography of Mixed-Mode Fracture in Soda Lime Silica Glass," J. Am. Ceram. Soc., 95 [11] 3622-7 (2012).

${ }^{22}$ R. L. Withers, T. R. Welberry, G. L. Hua, J. G. Thompson, and B. G. Hyde, "A Transmission Electron-Microscopy Study of Cristobalite," Phase Transitions, 16, 41-5 (1989).

${ }^{23}$ R. L. Withers, J. G. Thompson, and T. R. Welberry, "The Structure and Microstructure of Alpha-Cristobalite and Its Relationship to Beta-Cristobalite," Phys. Chem. Miner., 16 [6] 517-23 (1989). 